suspected by the practitioner or confessed by the patient), investigations to exclude gonorrhoea are rarely requested for men patients presenting with dysuria, frequency of micturition, or both. Moreover, in our cases gonococci in the urine were not overgrown by other organisms because we have two bench-cool trays (at $4^{\circ} \mathrm{C}$ ), one at the reception and the other within the laboratory, where samples of urine are processed so that all urine samples from the time of receipt to the time of disposal are kept chilled. Nor were the patients treated with any antibiotics before submission of specimens. It therefore seems logical to believe that gonorrhoea may also lead to "sterile" pyuria in women. In conclusion, we wonder whether gonorrhoea should be added to the list of conditions producing "sterile" pyuria in sexually active patients.

${ }^{1}$ Moore G, Pittard WB, Mosca N, O'Brien WM. Gonorrhea detection by urine sediment culture. $7 A M A$ 1973;224:1499-1501.

${ }^{2}$ Feng WC, Medeiros AA, Murray ES. Diagnosis of gonorrhea in male patients by culture of uncentrifuged first voided urine. $\mathcal{F} A M A$ 1977; 237:896-7.

(Accepted 15 fuly 1980)

Public Health Laboratory and Department of Microbiology, Whipps Cross Hospital, London E11 1NR

B CHATTOPADHYAY, MRCPATH, DCP, director and consultant microbiologist

I HALL, BSC, FIMLS, senior medical laboratory scientific officer

\section{Controlled trial of cromoglycate and slow-release aminophylline in perennial childhood asthma}

Cromoglycate and theophylline provide effective prophylactic treatment in childhood asthma. ${ }^{12}$ Slow-release theophylline preparations simplify treatment, and their use may improve patient compliance and control of symptoms. To assess this we have compared cromoglycate and slow-release aminophylline in a double-blind randomised crossover trial.

\section{Patients, methods, and results}

Seventeen boys and 13 girls aged 5-15 years with perennial asthma were studied. During three randomly assigned four-week periods each took cromoglycate, aminophylline, and placebo. They took cromoglycate or placebo four times daily and slow-release aminophylline or placebo twice daily. Throughout the trial all children used additional salbutamol as required. Persistent severe asthma was treated with a four-day course of prednisolone at home, or admission to hospital if necessary. Before the trial started the dose of slow-release aminophylline was adjusted to give peak plasma concentrations in the therapeutic range 56-112 $\mu \mathrm{mol} / 1(10-20 \mu \mathrm{g} / \mathrm{ml})$ 2.5-4 hours after the dose. ${ }^{3}$ The mean $( \pm \mathrm{SE})$ pretrial concentration was $89 \pm 6 \mu \mathrm{mol} / 1$.

Asthma was assessed by using diary cards, ${ }^{4}$ on which daily symptom scores, morning and evening peak expiratory flow rates (PEFR), all treatments taken, and possible side effects were recorded. Compliance with treatment was assessed from the diary cards, by counting tablets and capsules returned, and by measuring peak plasma theophylline concentrations at the end of each period of treatment. After completing the trial each child was asked which preparation he or she would prefer to take provided they were equally effective.
The table summarises the symptom scores, PEFR, and use of salbutamol. Mean daily symptom score and use of salbutamol was greater during the placebo period than during both active treatments. Mean PEFR was consistently lower during the placebo period. Mean daily symptom score was significantly lower during treatment with cromoglycate than during treatment with slow-release aminophylline. Although the mean number of symptom-free days was greater and the mean number of days with PEFR under half the predicted value was less during cromoglycate treatment than during slow-release aminophylline treatment, the differences were not significant. Possible side effects such as nausea, vomiting, abdominal pain and headache were recorded on $5 \%$ of trial days. They occurred with similar frequencies throughout all three periods. For severe attacks of asthma, eight children were admitted to hospital and four received prednisolone at home. Eight attacks occurred during placebo periods and two during each period of active treatment $(p<0.05)$

All prescribed aminophylline was taken on $94 \pm$ SE $3 \%$ of trial days while all cromoglycate was taken on only $81 \pm \operatorname{SE~} 5 \%$ of trial days $(p<0.05)$ Twice as many doses of cromoglycate, however, were prescribed. Thus equal proportions $(93 \%)$ of the total prescription of both drugs were taken. Mean plasma theophylline concentration during the trial was $71 \pm S E 6 \mu \mathrm{mol} / 1$. Some $80 \%$ of children preferred slow-release aminophylline tablets compared with $17 \%$ who preferred cromoglycate $(p<0.05)$; one child had no preference.

\section{Comment}

The results confirm that cromoglycate and theophylline are effective drugs in the prophylaxis of perennial asthma in children. Cromoglycate may have been more effective as this treatment was associated with the lowest symptom scores, but this was not confirmed by the other findings.

The willingness of patients to take prescribed treatment may determine the success or failure of prophylaxis in asthma. In this trial compliance with prescribed treatment was probably better for slowrelease aminophylline than for cromoglycate, because all doses were taken on significantly more days $(p<0 \cdot 05)$. Some $80 \%$ of the children said that they would prefer slow-release aminophylline if it was as effective as cromoglycate. Thus it might be taken more regularly for long periods. Slow-release aminophylline is also cheaper than cromoglycate, costing $£ 1.45$ a week compared with $£ 2.90$ (MIMS).

We are grateful to Napp for providing financial support for this trial. The statistical analyses and conclusions are our own independent assessments. Fisons kindly provided the cromoglycate and placebo. Mrs Sandra Newton and the hospital pharmacy staff allocated treatment.

${ }^{1}$ Hambleton G, Weinberger M, Taylor J, et al. Comparison of cromoglycate (Cromolyn) and theophylline in controlling symptoms of chronic asthma. Lancet 1977; i:381-5.

${ }^{2}$ Godfrey S, Balfour-Lynn I, König P. The place of Cromolyn sodium in the long term management of childhood asthma based on a 3 to 5 year follow up. 7 Pediatr 1975;87:465-73.

3 Weinberger M, Bronsky E. Evaluation of oral bronchodilator therapy in asthmatic children. $\mathcal{f}$ Pediatr $1974 ; 84: 421-7$.

${ }^{4}$ Connelly NM, Godfrey S. Assessment of the child with asthma. 7 Asthmo Res 1970;8:31-6.

${ }^{5}$ Godfrey S, Kamburoff PL, Nairn JR. Spirometry, lung volumes and airway resistance in normal children aged 5-18 years. $B r \mathcal{F}$ Dis Chest $1970 ; 64: 15-24$.

(Accepted 22 fuly 1980)

Department of Child Health, Royal Hospital for Sick Children Bristol BS2 8BJ

A T EDMUNDS, MA, MRCP, lecturer in child health

F CARSWELL, PHD, MRCP, senior lecturer and honorary consultant

PAT ROBINSON, BSC, research assistant

A O HUGHES, MSC, senior lecturer

Mean ( $\pm S E$ ) daily symptom scores, PEFR, doses of salbutamol, and number of symptom-free days during each treatment

\begin{tabular}{|c|c|c|c|c|c|c|c|}
\hline \multirow{2}{*}{ Treatment } & \multirow{2}{*}{$\begin{array}{l}\text { Symptom score } \\
(\text { maximum }=13)\end{array}$} & \multicolumn{3}{|c|}{ PEFR $(\%) \dagger$} & \multirow{2}{*}{$\begin{array}{l}\text { Salbutamol } \\
\text { (No of doses daily) }\end{array}$} & \multirow{2}{*}{$\begin{array}{c}\text { Symptom-free } \\
\text { days }(\%)\end{array}$} & \multirow{2}{*}{$\begin{array}{l}\text { Days when } \\
\text { PEFR }<50 \% \\
\text { predicted }(\%)\end{array}$} \\
\hline & & $\mathrm{am}$ & & $\mathrm{pm}$ & & & \\
\hline $\begin{array}{l}\text { Cromoglycate } \\
\text { Slow-release aminophylline } \\
\text { Placebo }\end{array}$ & $\left.\left.\begin{array}{l}1.69 \pm 0.08 \\
1.98 \pm 0.08 \\
2.27 \pm 0.08\end{array}\right\}^{* *}\right\}^{* * *}$ & $\left.\begin{array}{l}88 \pm 1 \\
88 \pm 1 \\
84 \pm 1\end{array}\right\}^{* * *}$ & $7^{* * *}$ & $\left.\left.\begin{array}{l}91 \pm 1 \\
91 \pm 1 \\
86 \pm 1\end{array}\right\}^{* * *}\right\}^{* * *}$ & $\left.\left.\begin{array}{l}0.95+0.05 \\
0.92 \\
1.24 \pm 0.04\end{array}\right\}^{* * *}\right\}^{* * *}$ & $\begin{array}{l}47 \pm 7 \\
40 \pm 6 \\
32 \pm 5\end{array}$ & $\begin{array}{l}47 \pm 9 \\
57 \pm 9 \\
60 \pm 9\end{array}$ \\
\hline
\end{tabular}

Difference between means significant: ${ }^{*} \mathrm{p}<0.05 ;{ }^{* *} \mathrm{p}<0.01 ; * * * \mathrm{p}<0.001$.

Difference between means significant: ${ }^{*} \mathrm{p}<0.05 ;{ }^{*} \mathrm{p}<0.01 ; * *$
PEFR as percentage of predicted normal from Godfrey et al. ${ }^{*}$ 